\title{
PVC Paste Rheology: Study of Process Dependencies
}

\author{
M.G. Rasteiro, ${ }^{1}$ A. Tomás, ${ }^{2}$ L. Ferreira, ${ }^{1}$ S. Figueiredo ${ }^{1}$ \\ ${ }^{1}$ Chemical Engineering Department, Coimbra University, Coimbra, Portugal \\ ${ }^{2}$ Companhia Industrial de Resinas Sintéticas, CIRES, S.A., Estarreja, Portugal
}

Received 24 June 2008; accepted 15 October 2008

DOI 10.1002/app.29931

Published online 24 February 2009 in Wiley InterScience (www.interscience.wiley.com).

\begin{abstract}
A plastisol is a dispersion (suspension) of fine particles of poly(vinyl chloride) with a plasticizer that is normally applied over a substrate, by spreading or coating, before the gelification and fusion into the final product. Because of the first step, the plastisol rheology study is a very important factor which has to be taken into consideration to determine and fine tune the process conditions.

This work is concerned with the study of the rheology of plastisols from selected PVC samples produced by the emulsion process, correlating it with the particle size distribution and surface characteristics from the polymer's powder and modifications during the plastisol aging pro-
\end{abstract}

cess. The results obtained show a significant influence of the original polymer properties in the viscosity aging and viscoelastic behaviour of the plastisol. First, a significant decrease in viscosity can be achieved by changing a particular surfactant during the polymerization step. Second, the type of particle aggregates present in the powder, can determine the evolution of the particle size in the plastisol which, in turn, correlates directly with the observed modifications in the aging and viscoelastic behavior. () 2009 Wiley Periodicals, Inc. J Appl Polym Sci 112: 2809-2821, 2009

Key words: PVC plastisol; rheology; particle size distribution; viscosity aging; surfactant; aggregates; oscillatory rheometry

\section{INTRODUCTION}

Poly(vinyl chloride) is an important world thermoplastic with inumerous applications. Although there are four known production processes, the suspension type represents around $80 \%$ of total commercial product, followed by the emulsion and micro-suspension type. ${ }^{1}$ Products from these later types are normally referred as dispersion resins, because of the premixing with plasticizers and other additives in the so called Plastisol or Paste process. The plastisol of poly(vinyl chloride) is a suspension of fine particles in a liquid plasticizer to produce a fluid like mixture that can be spread on to a substrate, poured into a mold, sprayed on to a surface, etc. ${ }^{2}$ The coated substrates are then heated in an oven to gel and fuse the material in to the final standard rubbery or foamed products. Because of the particular application type, the rheological behavior of each paste formulation, correlating with the characteristics of the initial polymer, has been continuously studied through several publications. ${ }^{3-7}$

The dispersion type polymers are normally made up with different particle sizes, some of them resulting from an agglomeration process during the drying of the original aqueous emulsion or microsuspension. Nevertheless, the agglomerated particles

Correspondence to: M.G. Rasteiro (mgr@eq.uc.pt).

Journal of Applied Polymer Science, Vol. 112, 2809-2821 (2009) (c) 2009 Wiley Periodicals, Inc. are not sufficiently strong to resist the high shearing mixing conditions, together with the solvating plasticizer effect over the polymer. This effect is normally translated by an increase of the plastisol viscosity with time, in a process normally called "viscosity aging" 2,5

The rheology of plastisols is also sensitive to the type of surfactants used during the polymerization process, type and quantity of plasticizer, and other additives used in the formulation, such as fillers and thermal stabilizers. ${ }^{2}$

The flow of the plastisol at room temperature normally follows the general rules of a concentrated suspension of solid particles in a Newtonian liquid. That is, the pseudoplastic behavior, and also the reported thixotropy under low stress, and dilatancy and fracture at high shear rates can be observed. ${ }^{6}$

At commonly used plasticized levels, for instance, 50-100 phr (parts of plasticizer per 100 parts of polymer), the particle size and size distribution (PSD) is an important control parameter for the later plastisol viscosity. Once a low viscosity level is normally required, a broader PSD is needed to achieve a maximum packing efficiency and, thus, to have more free liquid plasticizer per volume that acts as viscosity depressant. ${ }^{2,7}$

The viscosity aging phenomena can be related with several mechanisms, although the deagglomeration and the progressive plasticizer swelling by the polymer can justify the increase in viscosity because of the lower concentration of the liquid phase. ${ }^{5,7}$ 
Although less studied, the type of surfactant used during the emulsion polymerization or added just before latex drying, can represent a major contribute for the viscosity level and aging profile of a given plastisol formulation. ${ }^{2}$ The reasons for this can be related with the boundary thickness layer at the particle-plasticizer interface ${ }^{8}$ or with the agglomeration resistance of primary polymer particles. ${ }^{2,5}$

This study was aimed at identifying which particle characteristics most affect the rheology behavior of the pastes. For that we have fixed the particles composition (PVC of constant molecular weight) and the plasticizer (DIDP- Di-isodecyl Phthalate), having varied the particle size distribution of the PVC and the degree of aggregation by changing the polymerization operation parameters. The choice of DIDP as plasticizer, possessing a higher molecular weight than DOP (di-octyl phthalate), is in-line with the most recent safety recommendations, and represents an innovation to the studies in the same area usually reported in the literature, where DOP is normally used. The concentration of the plasticizer was also varied.

It had performed a systematic rheology characterization of the PVC pastes, both flow and dynamic tests, as aging proceeded. At the same time, the size distribution of the aggregates in the plastisols (for the same aging duration) was measured using a laser diffraction technique (LDS). Moreover, the zeta potential of the PVC aggregates was also determined. Additionally, some of the original PVC samples were (before being incorporated in the paste) visualized by scanning electron microscope (SEM).

\section{EXPERIMENTAL}

\section{Materials}

Emulsion PVC samples: From Companhia Industrial de Resinas Sintéticas, CIRES, S.A.

Plasticizer: Di-isodecyl Phtalate (DIDP), trade name Palatinol ${ }^{\circledR}$ 10P from BASF GmbH.

Thermal stabilizer: Mark BZ505 (Barium-Zinc) from Crompton Vinyl Additives $\mathrm{GmbH}$.

Organic solvent: n-Heptane (commercial grade).

\section{Plastisol samples preparation}

Commercial formulations of 100 and $70 \mathrm{phr}$ of DIDP were considered, with a common heat stability additive (Barium-Zinc) and the emulsion PVC samples. The preparation of the plastisols was carried out in a planetary mixer during $15 \mathrm{~min}$ to obtain a homogeneous final paste. While aging proceeded, the paste was kept in a closed chamber at a constant temperature $\left(23^{\circ} \mathrm{C}\right)$ and relative humidity $(\approx 35 \%)$.

\section{Particle size distribution}

Laser diffraction technique (LDS): Mastersizer 2000, Malvern Instruments, UK. LDS was used to measure the particle size distribution of the dry PVC powder in a diluted dispersion with n-heptane. Regarding the plastisol samples, according to the already published method, ${ }^{4}$ the dilution procedure was made with n-heptane. Moreover, LDS allowed one to also extract information about the mass fractal dimension of the aggregates. For a three dimensional aggregate the fractal dimension $\left(d_{F}\right)$ expresses the degree to which primary particles fill the space within the nominal volume occupied by the aggregate, according to eq. (1), and therefore is a convenient parameter to characterize the density of the aggregate. ${ }^{9}$ For solid nonporous particles $d_{F}=3$ and for porous particles $1<d_{F}<3$. $^{9}$ By recording the scattered light as a function of the magnitude of the scattering wave vector (q), the fractal dimension can be determined from the negative slope of the log-log plot of those two variables, ${ }^{10}$ according to eq. (2), applying a linear correlation. This implies that the primary particles obey the Rayleigh-Gans-Debye theory, valid for primary particles size below $0.5 \mu \mathrm{m}$.

$$
M \propto R^{d_{F}}
$$

Where, $M$ is the aggregate mass and $R$ the aggregate radius.

$$
\begin{gathered}
I \propto q_{F}^{-d_{F}} \\
q=\frac{\pi n \sin (\theta / 2)}{\lambda}
\end{gathered}
$$

Where, $I$ is the scattered light intensity, $n$ is the relative refractive index, $\theta$ is the scattering angle, and $\lambda$ is the incident light wavelength.

\section{Rheology measurements}

Controlled stress rheometer, Model RS1, Haake. The rheological tests were carried out in a controlled stress rheometer, with a sensor system Z34 DIN that comprises one rotor and one beaker, with a connected thermocontroller (constant temperature $23^{\circ} \mathrm{C}$ ). The spindle used had $20.00 \mathrm{~mm}$ (radius) at a clearance to bottom $7.2 \mathrm{~mm}$. For the plastisol samples, flow and dynamic tests were performed.

The flow tests allow one to characterize the rheological behavior of the pastes supplying information about the resistance to flow, a fundamental parameter to tune the final application conditions of the paste. Moreover, these tests are essential to evaluate the stability of the paste.

The oscillating, dynamic tests, supply information about the viscoelastic nature of the sample and enables to separate the viscous and elastic components 
TABLE I

PVC Powder Samples properties

\begin{tabular}{|c|c|c|c|c|c|c|c|}
\hline PVC sample & Surfactant & $K$ value & Zeta $(\mathrm{mV})$ & $d_{50}(\mu \mathrm{m})$ & $d_{90} / d_{10}$ & $\left(d_{90}-d_{10}\right) / d_{50}$ & $d_{F}$ \\
\hline E-PVC 1 & SLS & 70 & -53.0 & 12.53 & 7.8 & 2.5 & 2.1 \\
\hline E-PVC 2 & SLS & 70 & -51.6 & 29.25 & 4.8 & 1.7 & 2.0 \\
\hline E-PVC 3 & SABS & 69 & -46.8 & 24.72 & 4.5 & 1.6 & 1.9 \\
\hline E-PVC 4 & Unknown & 67 & -54.3 & 17.73 & 14.4 & 3.7 & 2.1 \\
\hline DIDP & \multicolumn{2}{|c|}{ Molecular weight $(\mathrm{g} / \mathrm{mol}) 446$} & \multicolumn{2}{|c|}{ Density $\left(\mathrm{kg} / \mathrm{cm}^{3}\right) 962$} & \multicolumn{3}{|c|}{ Viscosity $20^{\circ} \mathrm{C}$ (mPa s) 120} \\
\hline
\end{tabular}

of the material, respectively, the viscous modulus $\left(G^{\prime \prime}\right)$ and the elastic or storage modulus $\left(G^{\prime}\right) .{ }^{11}$ For that, frequency sweeps are conducted. For paste-like materials $G^{\prime}>G^{\prime \prime}$, for liquid like materials $G^{\prime \prime}>G^{\prime}$ and for solid materials it is also $G^{\prime \prime}>G^{\prime}$ but the difference between $G^{\prime}$ and $G^{\prime \prime}$ does not vary with frequency. ${ }^{11}$ The frequency sweep has to be conducted for a stress in the linear viscoelastic region so, to determine the linear viscoelastic range, a previous stress test was made.

Through oscillatory rheometry, it is possible to characterize materials with complex structures that are not revealed by the flow tests. The relation between the two modules, $G^{\prime \prime}$ and $G^{\prime}$, gives an indication of the structures that build within the suspension and of the modifications in those structures as the result of the aging process.

The flow tests results presented here are the average of at least two samples, for each sample at least two measurements were conducted.

\section{Zetasizer}

Zetasizer NanoZS, Malvern Instruments. A potential exists between the particle surface and the dispersing liquid, which varies according to the distance from the surface. The Zeta potential of the sample will determine whether the particles within a liquid will tend to stick together or not.

\section{Scanning electron microscope}

The SEM measurements were made with an Electron Microscope Leica \Cambridge S360: PVC samples were prepared on aluminum support with previous standard gold coating procedure.

\section{RESULTS AND DISCUSSION}

\section{Powder properties}

The emulsion PVC powder samples are listed on Table I, including the known type of main surfactant used during polymerization, commercial $\mathrm{K}$ (inherent viscosity method ISO 1628-2), zeta potential and PSD, namely the $d_{50}$, the distribution ratios $d_{90} / d_{10}$ and $\left(d_{90}-d_{10}\right) / d_{50}$.

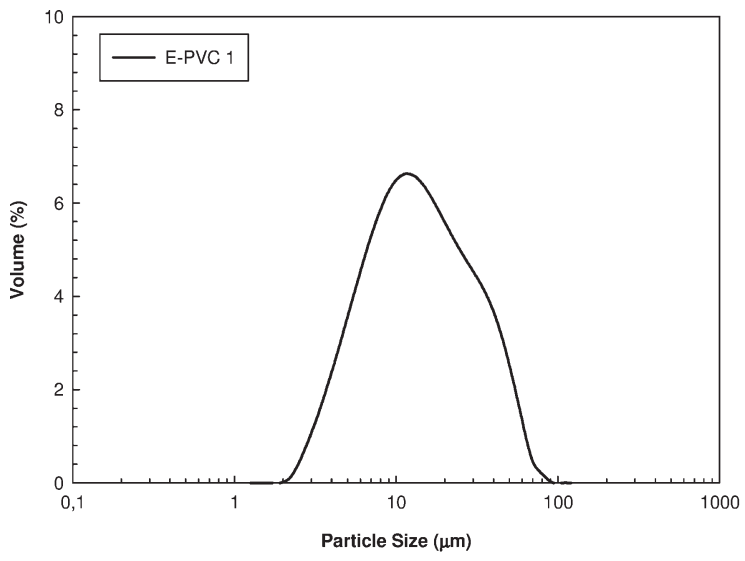

a) E-PVC1



b) E-PVC3

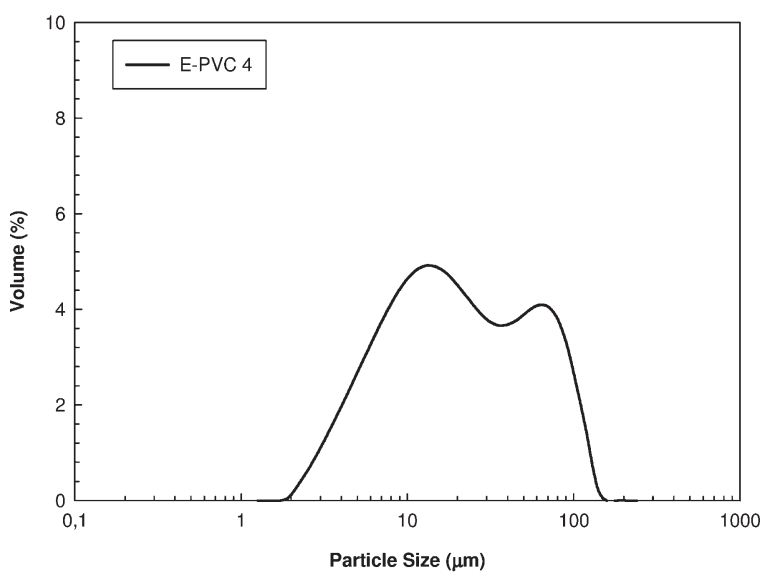

c) E-PVC4

Figure 1 PSD distributions (from LDS) of powder samples E-PVC 1,3,4. (a) E-PVC 1, (b) E-PVC 3, (c) E-PVC 4. 


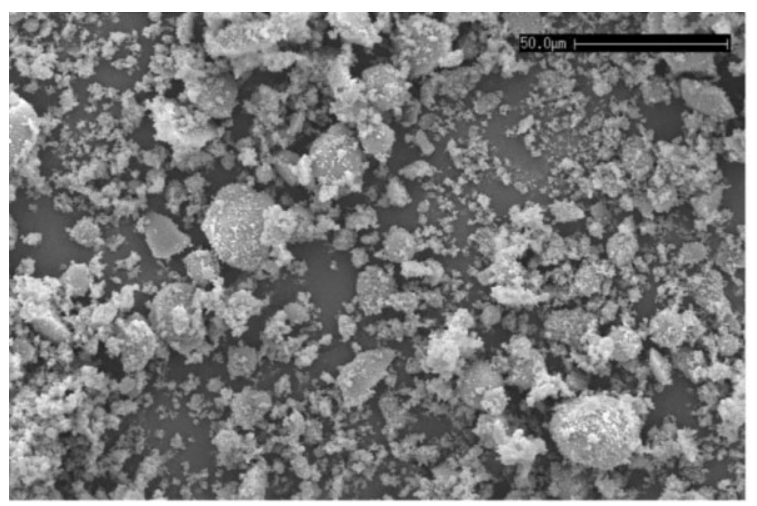

a) E-PVC 1



b) E-PVC 3

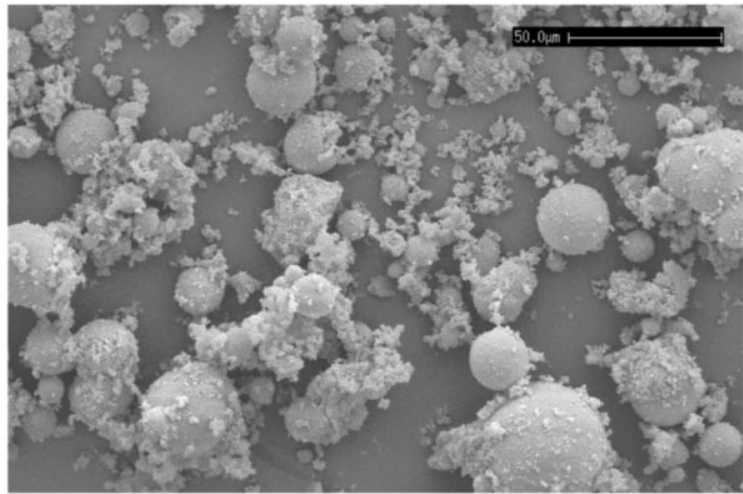

c) E-PVC 4

Figure 2 SEM analysis: Magnification $\times 500$. (a) E-PVC 1, (b) E-PVC 3, (c) E-PVC 4.

The main physical properties of the plasticizer DIDP used on the plastisol formulations are also given in Table I.

Considering the samples E-PVC 1 and 2, although the type of main surfactant is the same (sodium lauryl sulphate, SLS), E-PVC 1 is a regular commercial grade and E-PVC 2 is a trial sample produced in a pilot scale. This fact explains the significant differences on the PSD, which indicates a different level of particle agglomeration of the final powder.

E-PVC 3 is also a pilot sample, but produced with a different type of surfactant (SABS-sodium n-alkyl $\left(\mathrm{C}_{10}-\mathrm{C}_{13}\right)$ benzene sulphonate), keeping PSD as much the same as E-PVC 2, though the absolute value of zeta potential is lower. Regarding E-PVC 4, a standard grade on the market not produced by CIRES, S.A., although the $d_{50}$ has an intermediate value between E-PVC 1 and E-PVC 3, the higher ratio $d_{90} / d_{10}$ indicates a much broader PSD. Also, E-PVC 4 has the lowest $K$ value, followed by E-PVC 3 with just a small difference from the other samples.

Regarding the fractal dimension $\left(d_{F}\right)$, upon the results on Table I, there is no significant difference between all powder samples. Regarding the zeta potential, the lowest value is found for E-PVC 3, which must result in a higher degree of aggregation, agreeing with the lower ratio $d_{90} / d_{10}$.

Besides the numerical differences between the samples in Table I, the PSD curves from Figure 1 give a more effective indication of the type of size distribution of each sample, namely the continuous broader distribution of E-PVC 4, compared with EPVC 1 and 2, and the different class sizes of E-PVC 3. This difference is even more evident from the SEM analysis, since it confirms the PSD from the LDS technique (Figs. 2-4 for E-PVC 1, E-PVC 3, and E-PVC 4). Furthermore, it is evident from the SEM images [Figs. 2-4] the different stages of aggregation of the three samples (E-PVC 1, E-PVC 3, and E-PVC 4). E-PVC 1 is the one with more loose aggregates, while E-PVC 3 shows a larger number of compact aggregates of large size. In E-PVC 4 a large number of compact aggregates coexist with some loose aggregates. This clearly agrees with the PSD obtained by LDS where E-PVC 3 showed the largest median size value and the narrowest size distribution.

Moreover, increasing the magnification to $\times 5000$, the differences between the agglomerates of E-PVC 1, E-PVC 3, and E-PVC 4 [Fig. 4(a,b,c)] are revealed. The close packing of the E-PVC 4 [Fig. 4(c)] against 


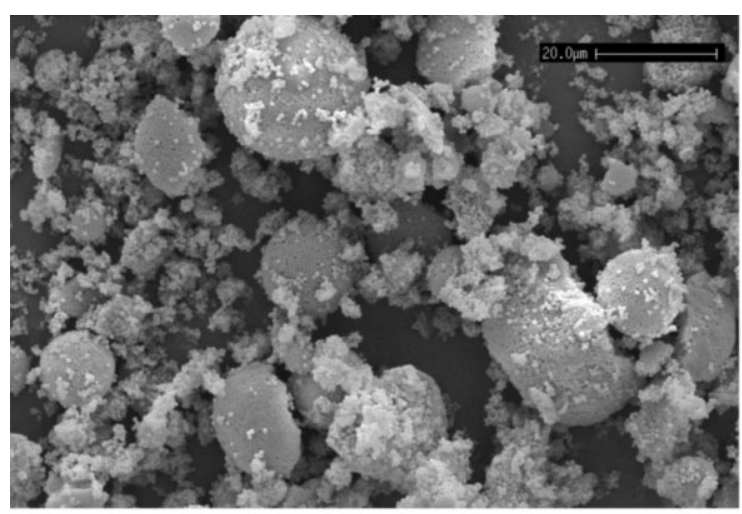

a) E-PVC1

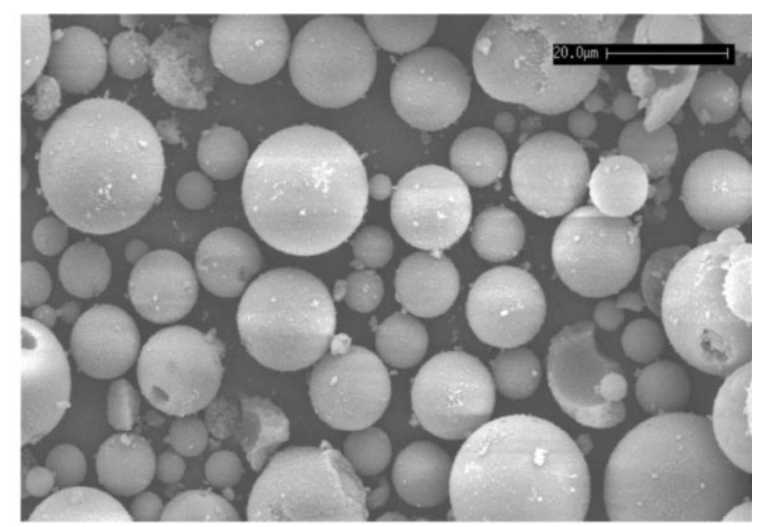

b) E-PVC3

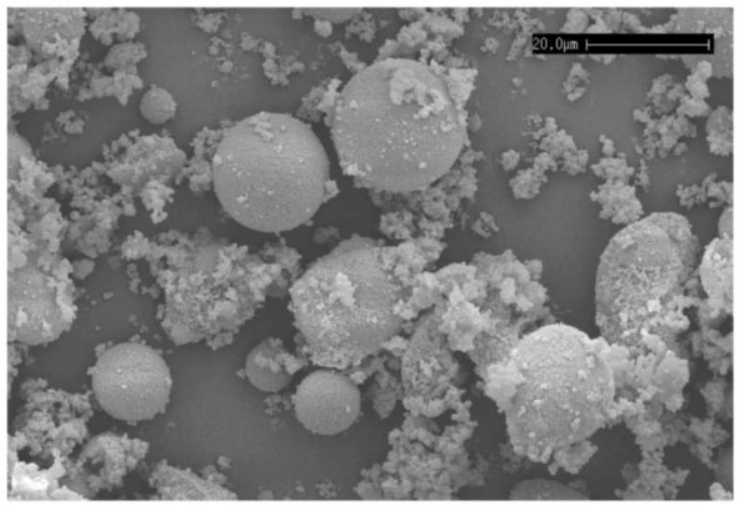

c) E-PVC4

Figure 3 SEM analysis: Magnification $\times 1000$. (a) E-PVC 1, (b) E-PVC 3, (c) E-PVC 4.

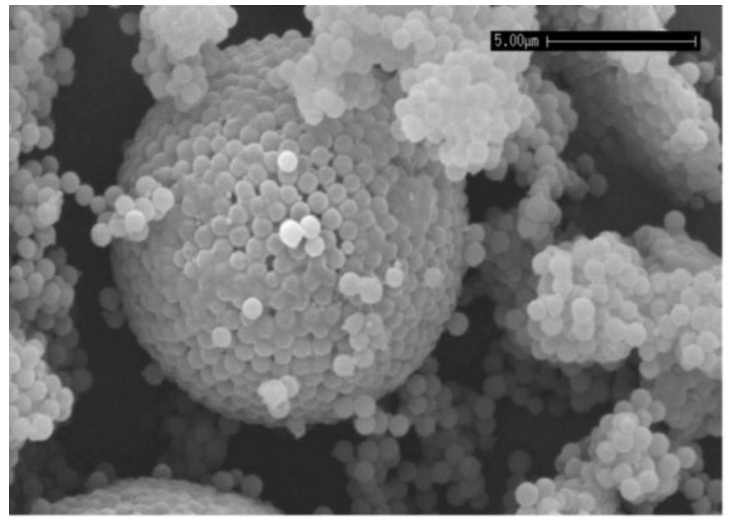

a) E-PVC1

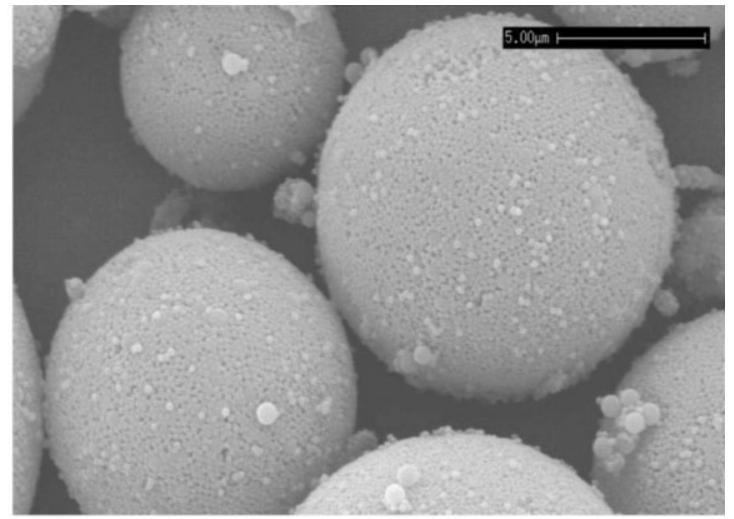

b) E-PVC3

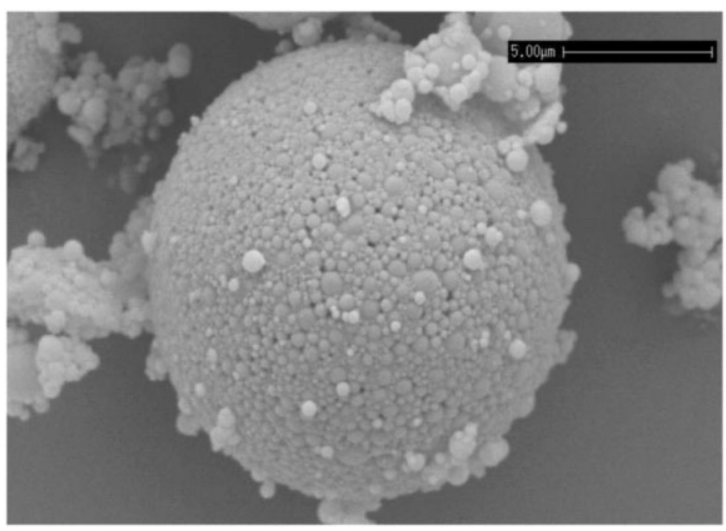

c) E-PVC4

Figure 4 SEM analysis: Magnification $\times 5000$. (a) E-PVC 1, (b) E-PVC 3, (c) E-PVC 4. 


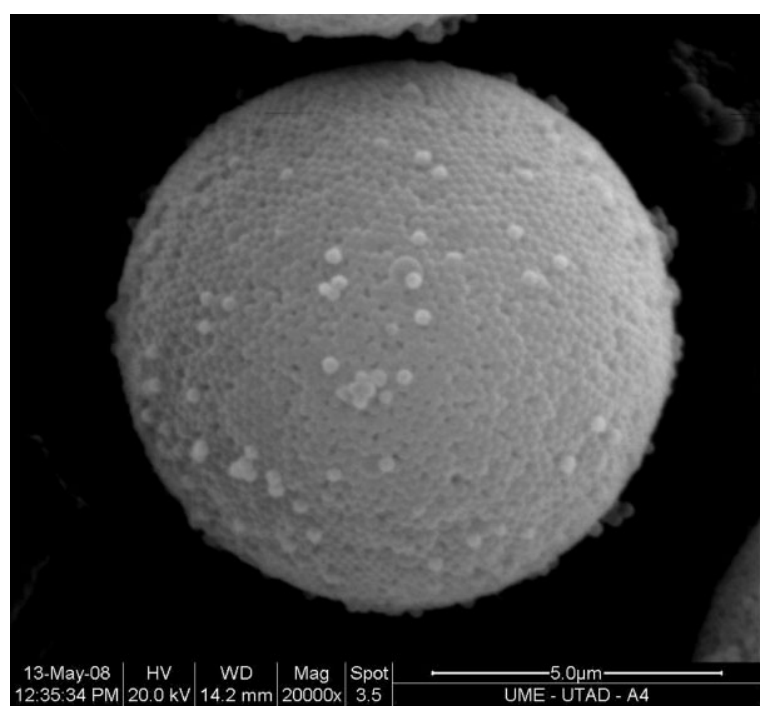

Figure 5 SEM analysis of EPVC 3: Magnification $\times 20,000$.

the irregular surface of E-PVC 1 [Fig. 4(a)]is evident. In the case of E-PVC 3 the large aggregates are also quite compact, though not as much as in the case of E-PVC 4 because the size distribution of the primary particles is narrower for the first sample (the individual particles are almost monosized). This can be more clearly observed for a magnification of $20,000 \times$ (Fig. 5).

The SEM images clearly reveal that changing the polymerization conditions (altering the surfactant) leads to different stages of aggregation in the final powder.

\section{Plastisol's formulations}

For each E-PVC sample, a plastisol was produced according to the referred procedure and formulation standards on Table II. Three types of formulations were tested, including the reference test to evaluate the thermal stabilizer additive's effect over rheology (P1 and P2) at 100 phr DIDP, and a different dosage of plasticizer from $100 \mathrm{phr}$ (P2, P3) to $70 \mathrm{phr}$ (P4, P5, and $\mathrm{P} 6$ ). Thus, comparing pastes $\mathrm{P} 2$ and $\mathrm{P} 4$ it is possible to evaluate the influence of the plasticizer dosage on the aging process. While comparing pastes
TABLE II

Plastisol's Formulations

\begin{tabular}{ccrc}
\hline & & DIDP & Stabilizer (Ba $\backslash \mathrm{Zn})$ \\
\cline { 3 - 4 } Plastisol & PVC Sample & \multicolumn{2}{c}{ phr } \\
\hline P1 & E-PVC 1 & 100 & - \\
P2 & E-PVC 1 & 100 & 2 \\
P3 & E-PVC 2 & 100 & 2 \\
P4 & E-PVC 1 & 70 & 2 \\
P5 & E-PVC 3 & 70 & 2 \\
P6 & E-PVC 4 & 70 & 2 \\
\hline
\end{tabular}

P2 and P3 and P4, P5 and P6 the influence of the PVC characteristics on aging is evaluated for two different levels of plasticizer.

The general trend in the aging profile of the plastisols considers that there is a great increase in the viscosity level until one week after the preparation. This fact was referred and followed by Nakajima and Har$\mathrm{rel}^{5}$ considering previous publications in the same research area. However, in the industrial practice, several control points are considered to define the correct process conditions of the paste. Namely, at 1 and $3 \mathrm{~h}$ to have a first knowledge over the plastisol behavior, and at $24 \mathrm{~h}$, that normally matches with the final application of the paste. To have a complete study of the paste samples in a one-week period, three more control points were considered, namely 48, 120, and $168 \mathrm{~h}$ after the preparation of the sample.

Therefore, the six different plastisol samples from Table II were controlled according to the said control points, applying the referred analysis methods, and procedures.

\section{Plastisol's PSD during aging}

Considering the stated experimental procedure, Table III summarizes the PSD distribution of the plastisol during the aging time from $1 \mathrm{~h}$ to $168 \mathrm{~h}$ (7 days) after preparation. In Table IV, the width of the size distribution is evaluated by using the ratio $\left(d_{90}-d_{10}\right) / d_{50}$.

Comparing with the PSD results from the powder samples (Table I), there is a general decrease on $d_{50}$ just $1 \mathrm{~h}$ after the plastisol's preparation. This fact is directly correlated with the plasticizer solvent effect

TABLE III

Particle Size Distributions of Plastisols During Aging

\begin{tabular}{|c|c|c|c|c|c|c|c|c|c|c|c|c|}
\hline \multirow[b]{2}{*}{ Plastisol } & \multicolumn{6}{|c|}{$d_{50}(\mu \mathrm{m})$} & \multicolumn{6}{|c|}{$d_{90} / d_{10}$} \\
\hline & $1 \mathrm{~h}$ & $3 \mathrm{~h}$ & $24 \mathrm{~h}$ & $48 \mathrm{~h}$ & $120 \mathrm{~h}$ & $168 \mathrm{~h}$ & $1 \mathrm{~h}$ & $3 \mathrm{~h}$ & $24 \mathrm{~h}$ & $48 \mathrm{~h}$ & $120 \mathrm{~h}$ & $168 \mathrm{~h}$ \\
\hline P1 & 10.20 & 10.73 & 13.69 & 15.14 & 18.60 & 19.15 & 6.8 & 7.0 & 5.0 & 4.3 & 5.5 & 6.3 \\
\hline P2 & 12.07 & 11.69 & 11.21 & 11.79 & 11.74 & 10.88 & 7.0 & 5.3 & 5.5 & 6.8 & 6.7 & 7.2 \\
\hline P3 & 23.86 & 23.75 & 24.50 & 25.45 & 24.18 & 23.71 & 6.5 & 6.3 & 7.8 & 3.5 & 3.4 & 7.0 \\
\hline P4 & 10.25 & 10.07 & 10.84 & - & 9.75 & 10.32 & 6.1 & 6.3 & 6.8 & - & 6.3 & 7.2 \\
\hline P5 & 17.37 & 19.61 & 18.49 & 19.58 & 18.67 & 18.64 & 11.9 & 11.6 & 10.5 & 11.1 & 10.9 & 10.6 \\
\hline P6 & 10.95 & 10.13 & 11.37 & 10.08 & 10.40 & 9.71 & 8.3 & 11.0 & 10.8 & 10.5 & 10.1 & 10.4 \\
\hline
\end{tabular}


TABLE IV

Particle Size Distributions and Fractal Dimension

\begin{tabular}{|c|c|c|c|c|c|c|c|c|}
\hline \multirow[b]{2}{*}{ Plastisol } & \multicolumn{6}{|c|}{$\left(d_{90}-d_{10}\right) / d_{50}$} & \multicolumn{2}{|c|}{$d_{F}$} \\
\hline & $1 \mathrm{~h}$ & $3 \mathrm{~h}$ & $24 \mathrm{~h}$ & $48 \mathrm{~h}$ & $120 \mathrm{~h}$ & $168 \mathrm{~h}$ & $1 \mathrm{~h}$ & $168 \mathrm{~h}$ \\
\hline P1 & 2.7 & 2.7 & 1.8 & 1.6 & 2.0 & 2.2 & 2.2 & 2.0 \\
\hline P2 & 2.1 & 1.5 & 1.6 & 2.1 & 2.0 & 2.4 & 2.2 & 2.1 \\
\hline P3 & 2.0 & 1.8 & 2.3 & 1.3 & 1.9 & 2.1 & 2.1 & 2.0 \\
\hline P4 & 2.1 & 2.3 & 2.2 & - & 2.4 & 2.3 & 2.2 & 2.1 \\
\hline P5 & 2.8 & 2.6 & 2.5 & 2.5 & 2.6 & 2.6 & 2.1 & 2.0 \\
\hline P6 & 2.7 & 3.9 & 3.2 & 3.4 & 3.5 & 3.9 & 2.2 & 2.3 \\
\hline
\end{tabular}
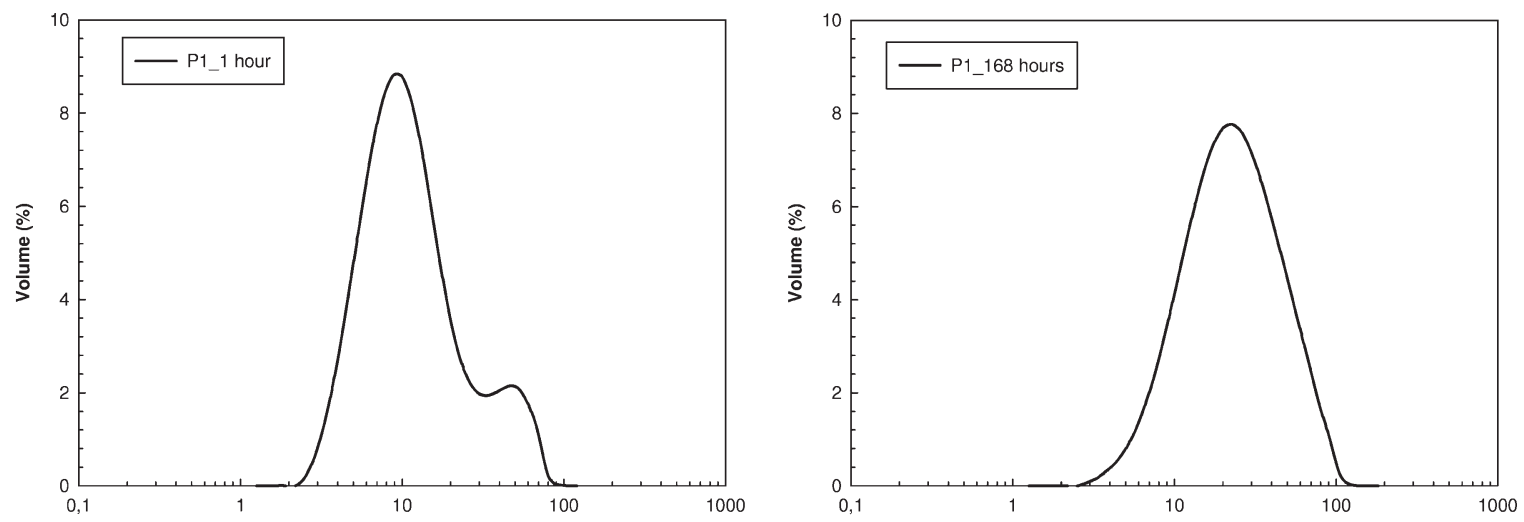

a) P1 at $1 \mathrm{~h} \quad$ Particle size ( $\mu \mathrm{m})$

b) P1 at $168 \mathrm{~h}$

Particle size $(\mu \mathrm{m})$

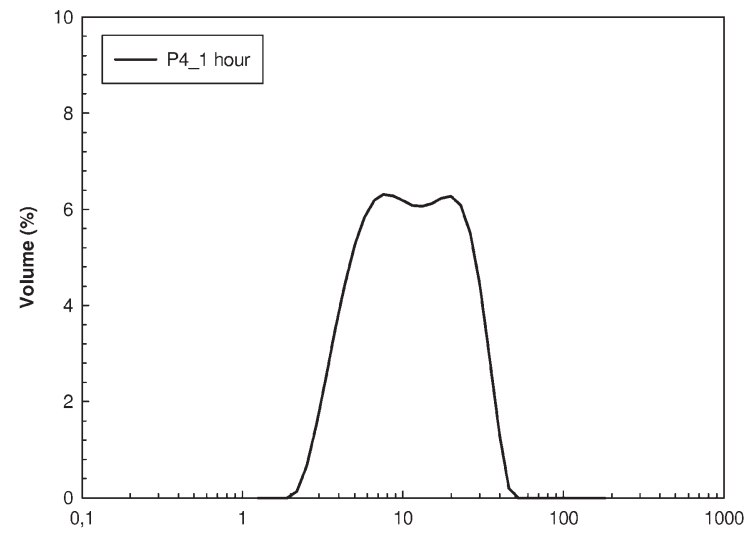

c) P4 at $1 \mathrm{~h}$

Particle Size $(\mu \mathrm{m})$

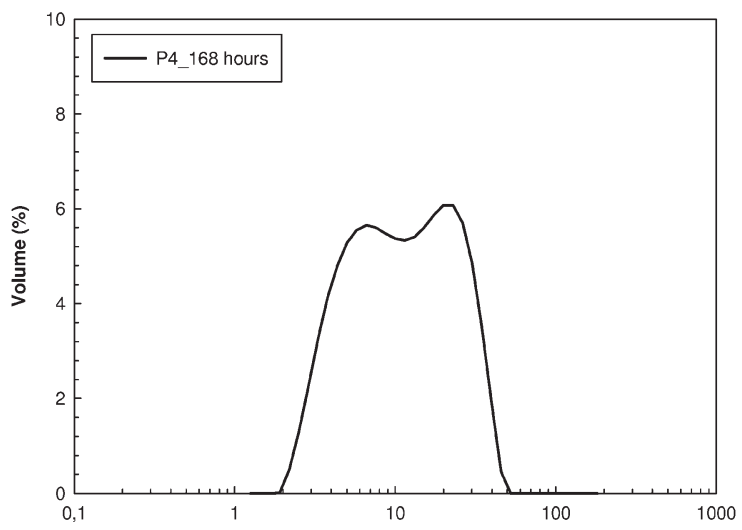

d) P4 at $168 \mathrm{~h}$

Particle Size $(\mu \mathrm{m})$
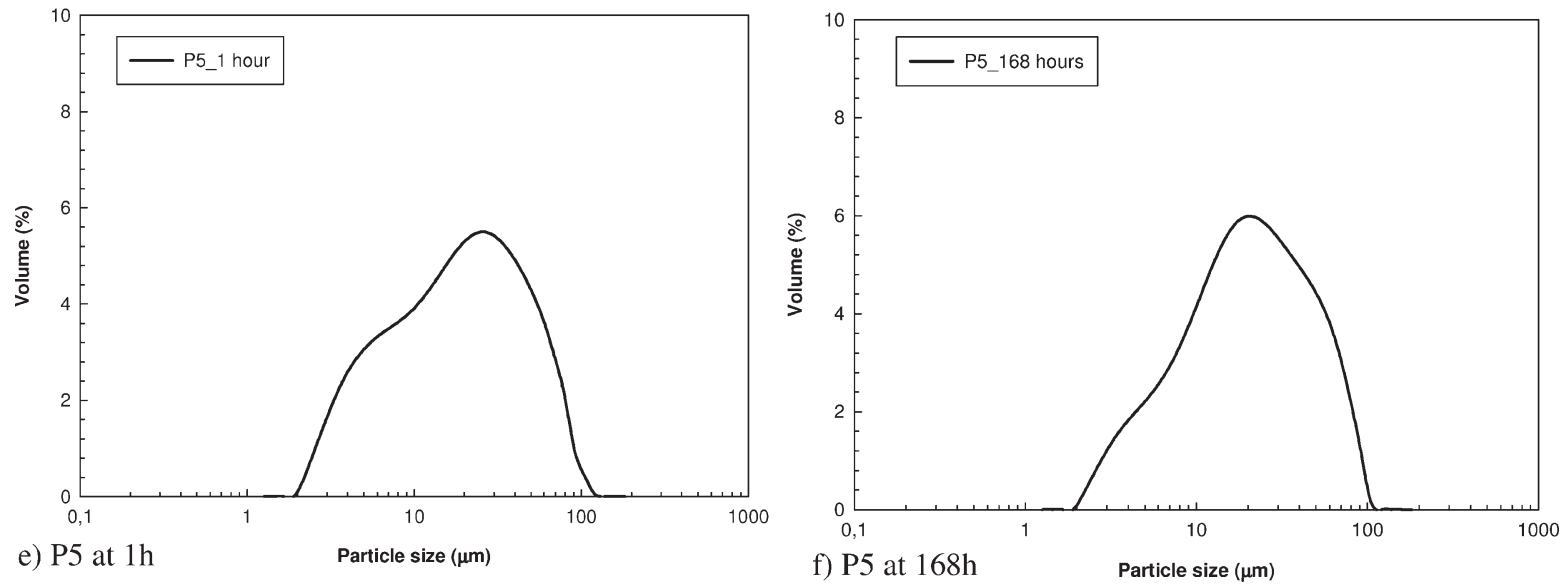

Figure 6 PSD distributions (from LDS) of plastisols samples P1, P4, P5, and P6 from $1 \mathrm{~h}$ to $168 \mathrm{~h}$. (a) P1 at $1 \mathrm{~h}$, (b) P1 at $168 \mathrm{~h} \mathrm{(c)} \mathrm{P4} \mathrm{at} 1 \mathrm{~h},(\mathrm{~d}) \mathrm{P} 4$ at $168 \mathrm{~h},(\mathrm{e}) \mathrm{P} 5$ at $1 \mathrm{~h}$, (f) P5 at $168 \mathrm{~h},(\mathrm{~g}) \mathrm{P} 6$ at $1 \mathrm{~h},(\mathrm{~h}) \mathrm{P} 6$ at $168 \mathrm{~h}$. 

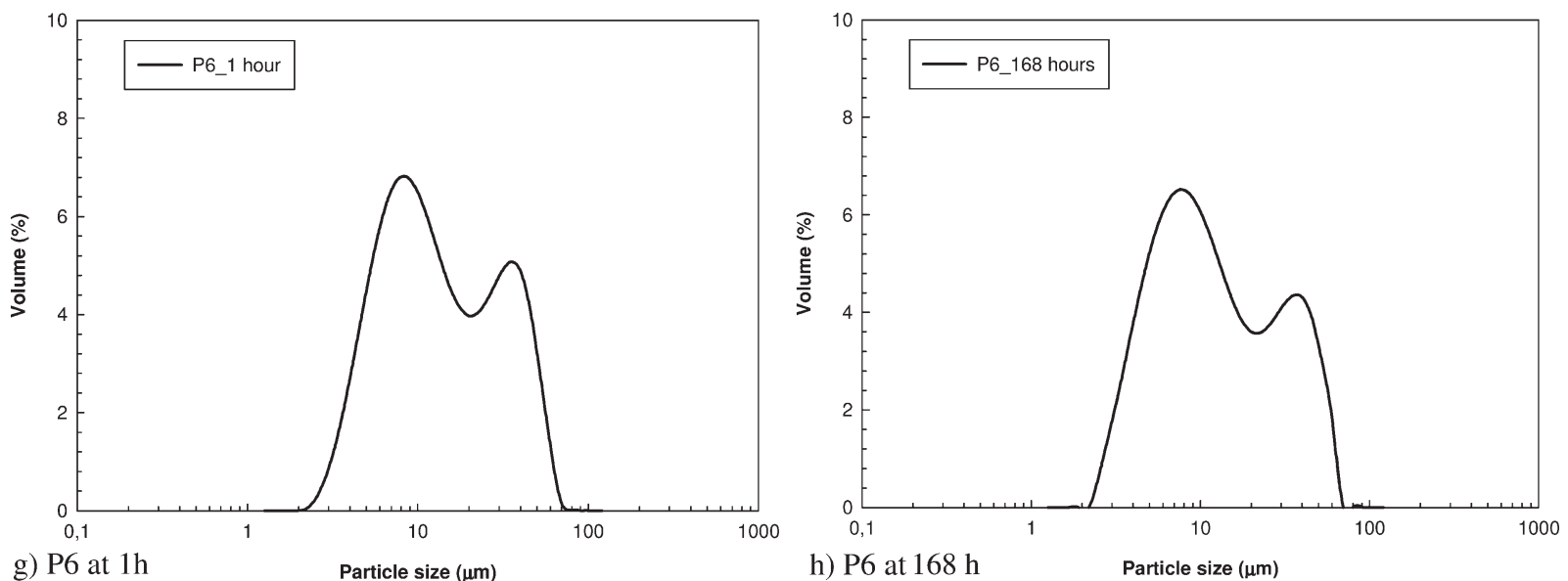

Figure 6 (Continued from the previous page)

over the particle's aggregates during the aging period. Also, excluding P3 and $\mathrm{P} 5$, the ratio $d_{90} / d_{10}$ decreases initially $(1 \mathrm{~h})$, indicating the destruction of the loose agglomerates in an earlier stage.

Considering P1 and P2, made with the same powder sample (E-PVC 1), the evolution during aging from $1 \mathrm{~h}$ to $48 \mathrm{~h}$, is more pronounced on P1. This fact can be related with the thermal stabilizer used on P2's formulation and, as a possibility, the decrease of the plasticizer solvating effect or the existence of less friable agglomerates in P2 due to surface effects caused by the stabilizer.

Regarding the plastisol P3, made from the pilot sample E-PVC 2 , there is only a slight decrease of $d_{50}$ from the powder to the initial stage of the plastisol. That is, although with the same surfactant type, the difference in the production process, namely scaledown circumstances and spray drying conditions, induces different properties of the final product.

From Table IV, all the plastisols have a quite broad PSD, although P5 and markedly P6 have the larger width through all the aging period. With the exception of $\mathrm{P} 6$, the fractal dimension $\left(d_{F}\right)$ decreases from 1 to $168 \mathrm{~h}$, revealing the destruction of some of the agglomerates. In fact, in Figure 6, which presents the typical evolution of the PSD from the tested plastisol's samples (P1, P4, P5, and P6), it is clearly demonstrated the PSD stability of P6 against the observed destruction of the agglomerates on P5 and mainly P1. Comparing P1 and P4, the last one prepared with stabilizer in opposition to P1, the destruction of the fine aggregates from 1 to $168 \mathrm{~h}$ is more evident in P1. In P5, the existence of small aggregates at $168 \mathrm{~h}$ is still less notorious. This agrees with the analysis of SEM images. In fact, E-PVC 1, used in the preparation of $\mathrm{P} 1, \mathrm{P} 2$, and $\mathrm{P} 4$ possesses a smaller amount of large aggregates which are also less compact. As for E-PVC 4 used in the preparation of P6, a higher number of large and more compact aggregates have been found, while in E-PVC 3, used in the preparation of $\mathrm{P} 5$, the number of large aggregates is also high but they are, in general, less compact than in the case of E-PVC 4.

Referring to the influence of the plasticizer dosage (compare P2 and P4) no significant effect on PSD was observed.

\section{Plastisol's flow properties during aging}

The flow tests results on Table $\mathrm{V}$ and Figure 7 can be directly related with the observations made above regarding the PSD evolution. That is, the less compact the agglomerates on powder, greater the modifications on paste and the observed increase in limit viscosity and hysteresis through all the aging period. Considering the difference on formulation between P1 and P2, the thermal Ba-Zn stabilizer acts as a viscosity aging depressant and reduces the non-Newtonian behavior.

For the same plasticizer dosage, plastisol P5 exhibits a very low limit viscosity during the aging period, denoting the influence of the different surfactant on the surface of the polymer's particles. Nevertheless, after $48 \mathrm{~h}$, there is an increase in the hysteresis area, indicating that the agglomerates could no further resist to the solvating effect of the plasticizer over the polymer. Furthermore, although the information about the surfactant type of E-PVC 4 is not provided, the correspondent plastisol P6 has the lowest viscosity and hysteresis during aging, which correlates directly with the constant broader PSD of plastisol [Fig. 6(g,h)].

Taking into consideration again the SEM images, P4, possessing a lower number of agglomerates, which are simultaneously less compact, has got a higher tendency for solvating and, thus, a more pronounced aging and a higher viscosity because of the larger surface area. P6 is in the other extreme: large number of very compact aggregates and thus lower viscosity and less pronounced aging. In the case of 
TABLE V

Flow Tests of Plastisols During Aging

\begin{tabular}{|c|c|c|c|c|c|c|c|c|c|c|c|c|c|c|c|c|c|}
\hline \multirow[b]{2}{*}{ Plastisol } & \multicolumn{6}{|c|}{ Limit viscosity (Pa s) } & \multicolumn{5}{|c|}{ Relative increase in $\mu(\%)$} & \multicolumn{6}{|c|}{ Hysteresis $/ \gamma(\mathrm{Pa})$} \\
\hline & $1 \mathrm{~h}$ & $3 \mathrm{~h}$ & $24 \mathrm{~h}$ & $48 \mathrm{~h}$ & $120 \mathrm{~h}$ & $168 \mathrm{~h}$ & $3 \mathrm{~h}$ & $24 \mathrm{~h}$ & $48 \mathrm{~h}$ & $120 \mathrm{~h}$ & $168 \mathrm{~h}$ & $1 \mathrm{~h}$ & $3 \mathrm{~h}$ & $24 \mathrm{~h}$ & $48 \mathrm{~h}$ & $120 \mathrm{~h}$ & $168 \mathrm{~h}$ \\
\hline P1 & 6.9 & 7.0 & 7.9 & 8.6 & 9.2 & 9.2 & 2 & 14 & 24 & 34 & 34 & 5.3 & 7.4 & 18.2 & 24.8 & 26.9 & 24.7 \\
\hline P2 & 7.2 & 7.0 & 7.2 & 7.0 & 6.6 & 6.4 & -2 & 1 & -2 & -8 & -10 & 5.6 & 1.1 & 3.2 & 10.6 & 14.4 & 17.5 \\
\hline P3 & 13.2 & 15.1 & 17.8 & 13.8 & 18.2 & 14.0 & 14 & 35 & 5 & 38 & 6 & 12.0 & 13.5 & 12.7 & 16.2 & 25.3 & 15.5 \\
\hline P4 & 16.0 & 16.5 & 15.8 & - & 17.0 & 17.8 & 3 & -1 & - & 6 & 11 & 45.5 & 64.6 & 53.0 & - & 43.5 & 37.8 \\
\hline P5 & 12.9 & 9.3 & 10.7 & 9.3 & 10.0 & 9.7 & -28 & -17 & -28 & -22 & -24 & 141.0 & 102.5 & 117.8 & 123.9 & 134.4 & 134.8 \\
\hline P6 & 4.8 & 4.9 & 4.7 & 4.7 & 4.7 & 4.6 & 1 & -3 & -3 & -3 & -4 & 3.4 & 2.6 & 1.8 & 1.9 & 2.9 & 2.9 \\
\hline
\end{tabular}
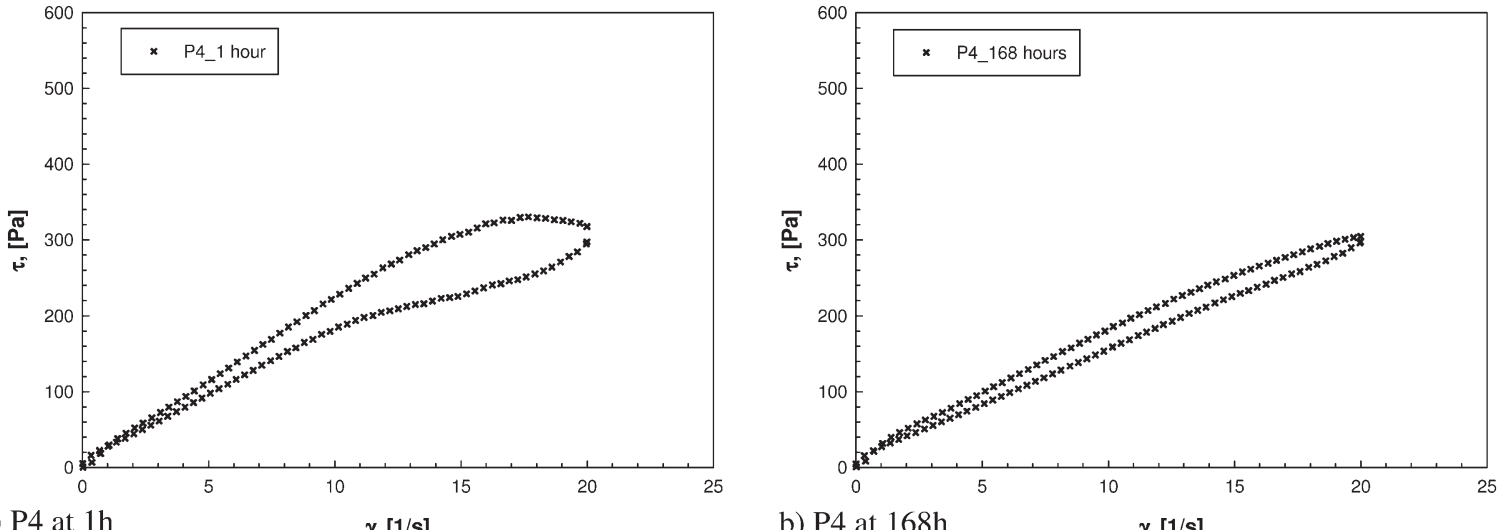

a) $\mathrm{P} 4$ at $1 \mathrm{~h}$

b) P4 at $168 \mathrm{~h}$
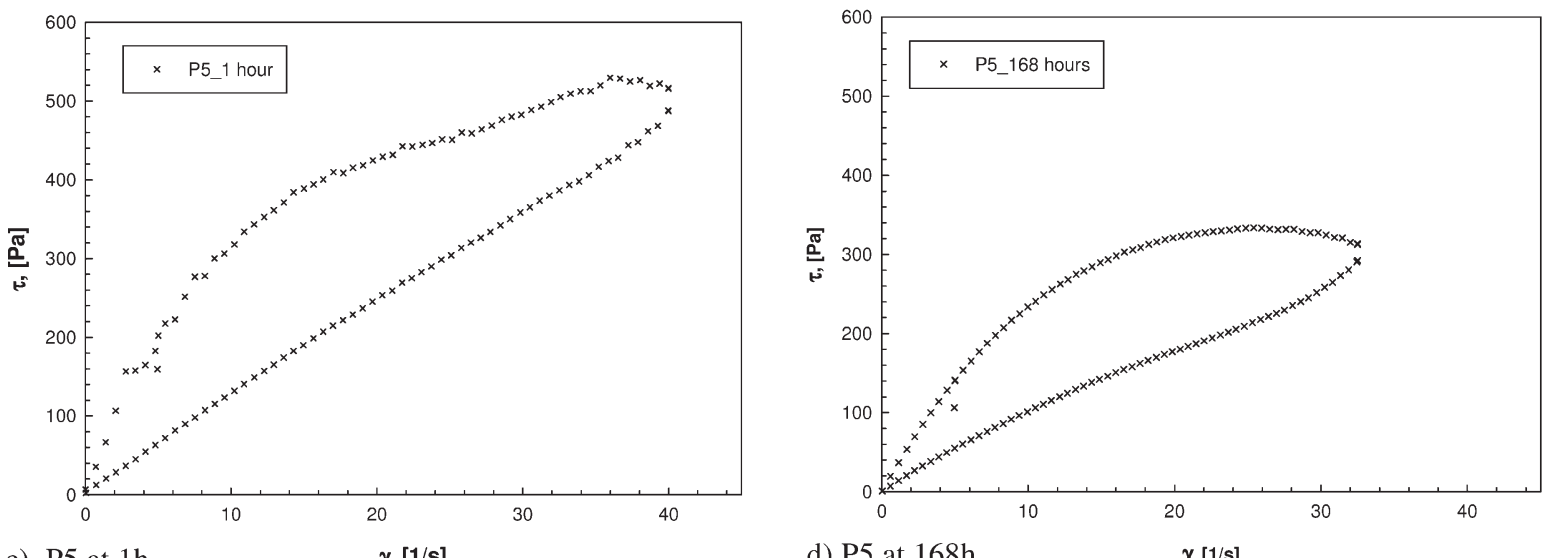

c) P5 at $1 \mathrm{~h}$

d) P5 at $168 \mathrm{~h}$
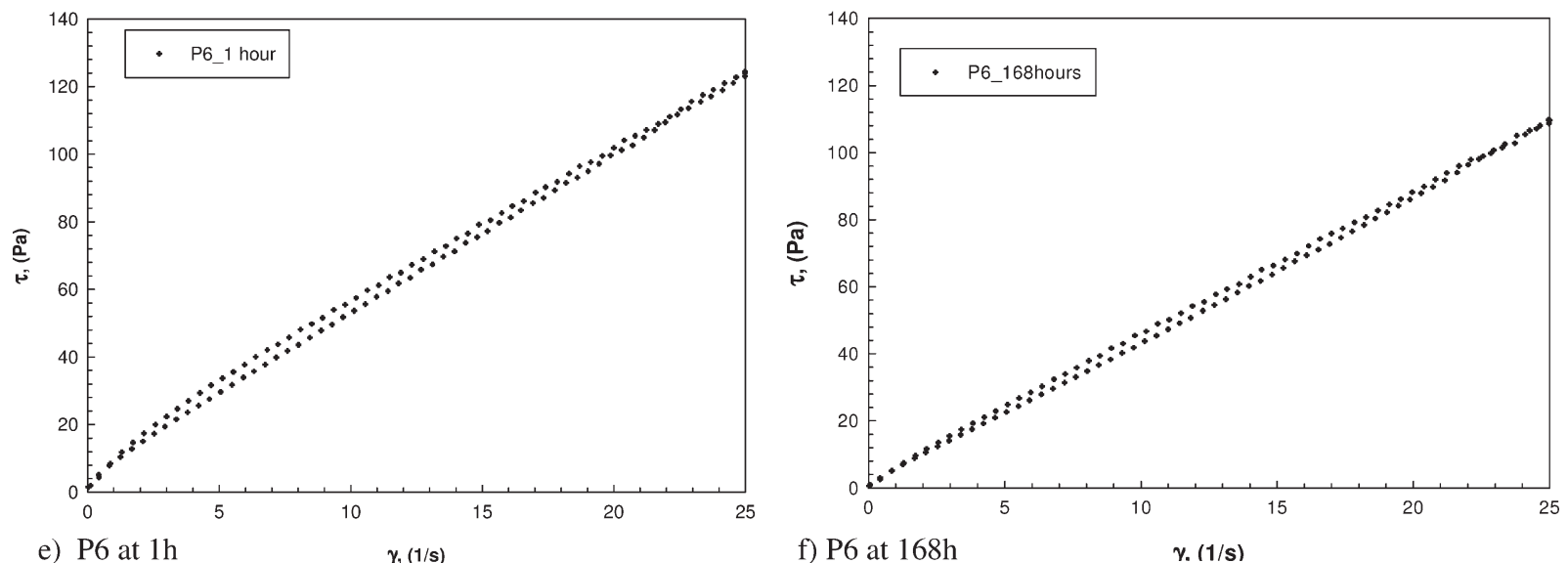

Figure 7 Flow tests of plastisol samples P4, P5, and P6 at $1 \mathrm{~h}$ and $168 \mathrm{~h}$. (a) P4 at $1 \mathrm{~h}$, (b) P4 at $168 \mathrm{~h}$, (c) P5 at $1 \mathrm{~h}$, (d) P5 at $168 \mathrm{~h},(\mathrm{e}) \mathrm{P} 6$ at $1 \mathrm{~h}$, (f) P6 at $168 \mathrm{~h}$. 


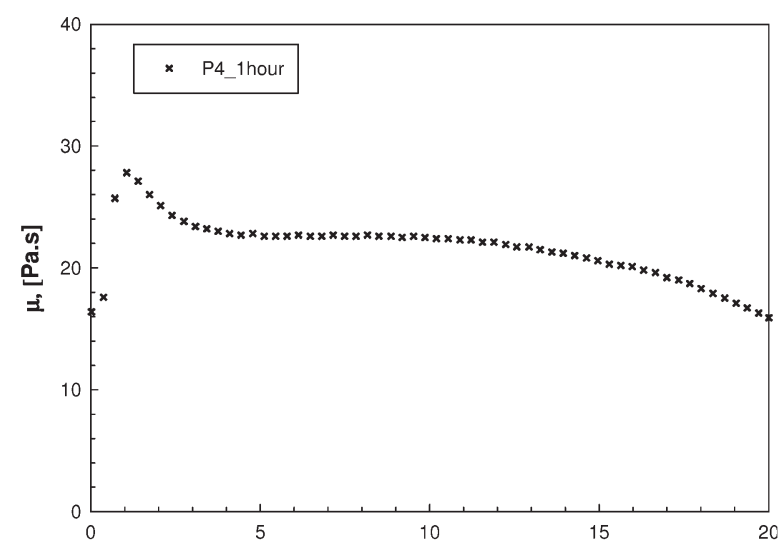

a) P4 at $1 \mathrm{~h}$

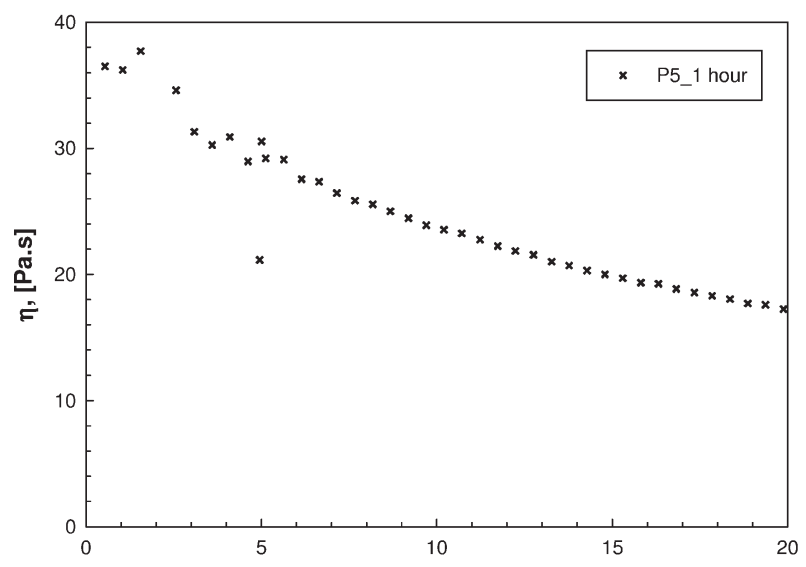

c) P5 at $1 \mathrm{~h}$

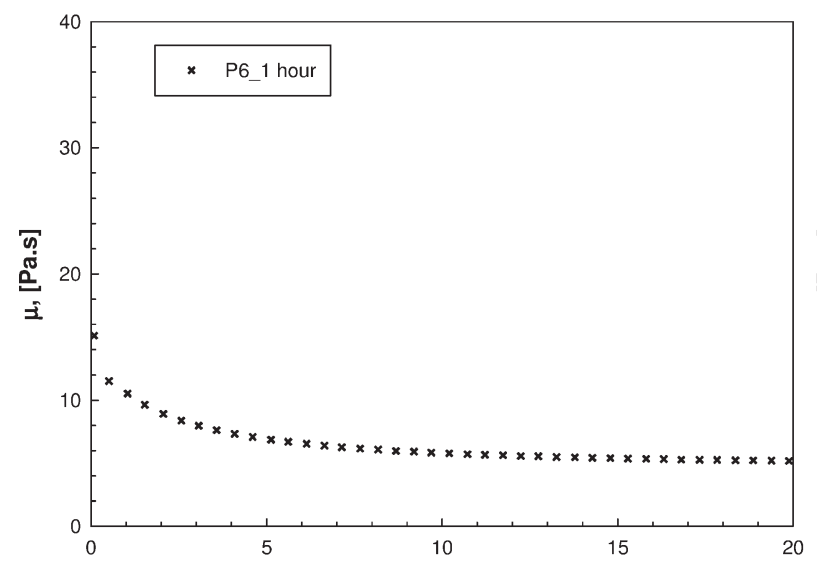

e) P6 at $1 \mathrm{~h}$

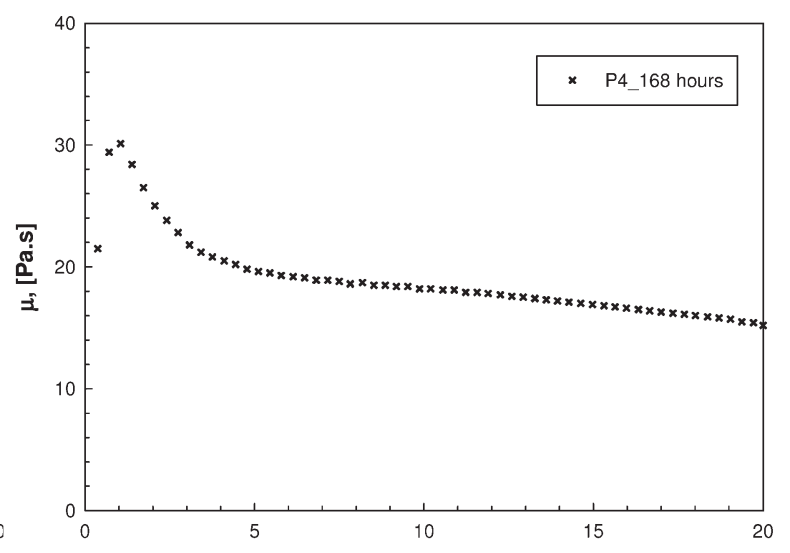

b) P4 at $168 \mathrm{~h} \quad \gamma,[1 / \mathrm{s}]$

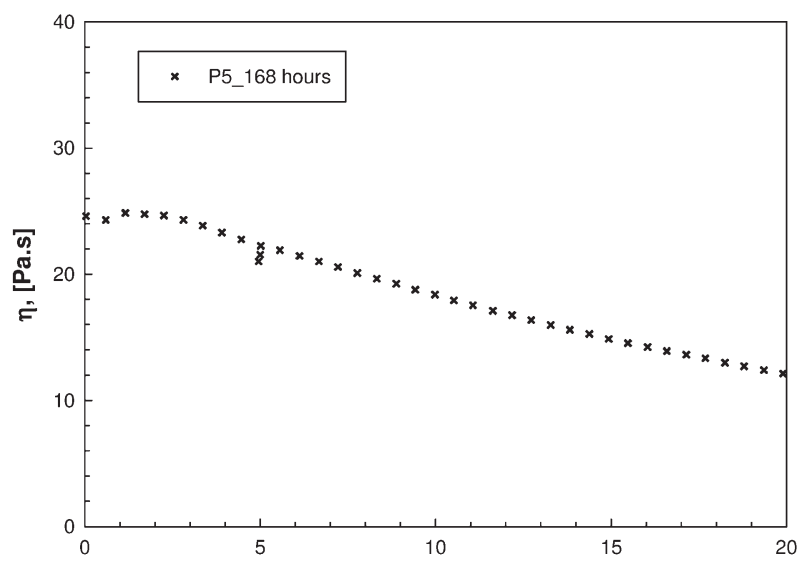

d) P5 at $168 \mathrm{~h} \quad \gamma,[1 / \mathrm{s}]$

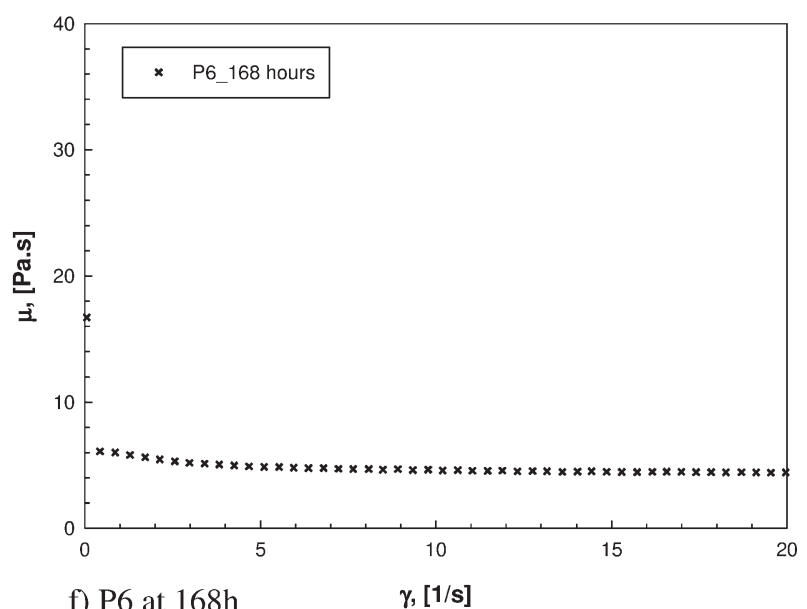

f) $\mathrm{P} 6$ at $168 \mathrm{~h}$

Figure 8 Viscosity versus shear rate for plastisol samples P4, P5, and P6 at $1 \mathrm{~h}$ and $168 \mathrm{~h}$. (a) P4 at $1 \mathrm{~h}$, (b) P4 at $168 \mathrm{~h}$, (c) P5 at 1 h, (d) P5 at 168 h, (e) P6 at 1 h, (f) P6 at $168 \mathrm{~h}$.

P5, with a high number of large and not so compact aggregates there is some solvating effect and, thereafter, aging shows an intermediate behavior.

Considering the flow tests from Figure 7, for the same paste formulation, the differences reported between P4, P5 and P6 can be further demonstrated analyzing the shear stress range over the applied shear rate. That is, on the contrary of P4 and P5, P6 has a constant behavior during aging with a very low hysteresis. The very high hysteresis area of P5 must be related with the different surface properties of the E-PVC 3 as a result of the different surfactant used (lower zeta potential).

The differences on rheology are stated again on Figure 8 , with the growing level of viscosity $(\mu)$ over the shear rate $(\gamma)$ applied for the samples: P4 $>$ P5 $>$ P6. 


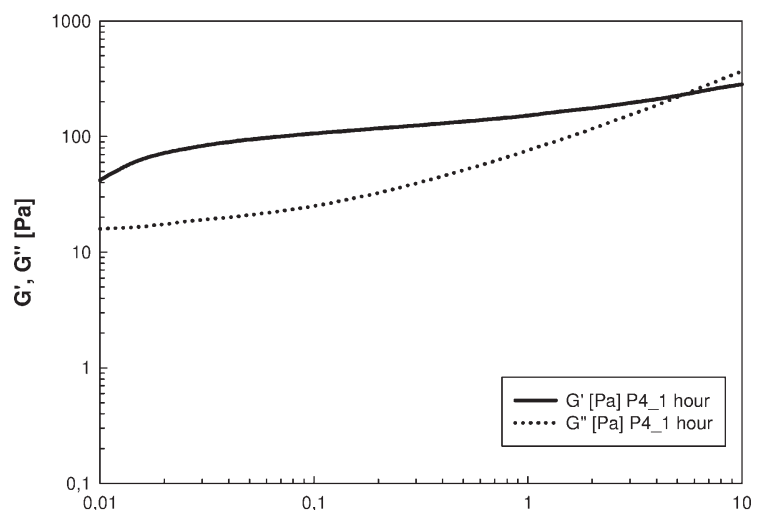

a) $\mathrm{P} 4$ at $1 \mathrm{~h} \quad \mathrm{f},[\mathrm{Hz}]$
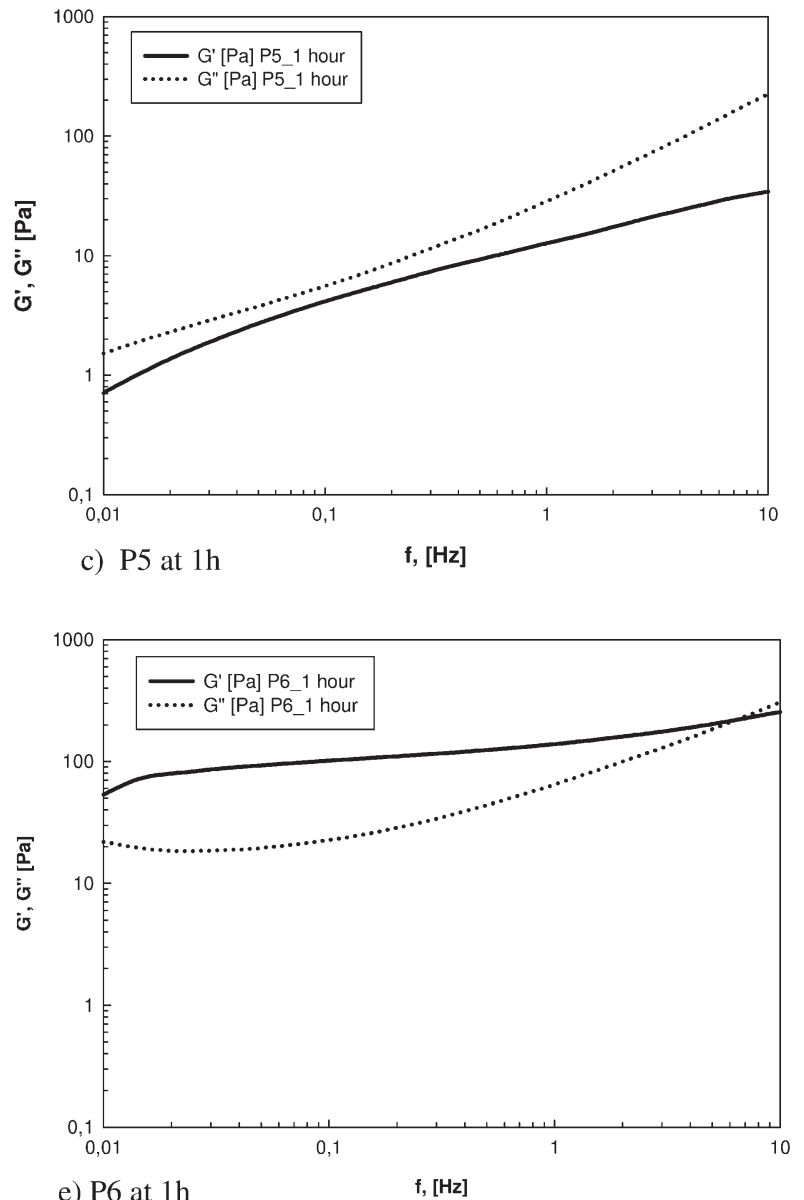

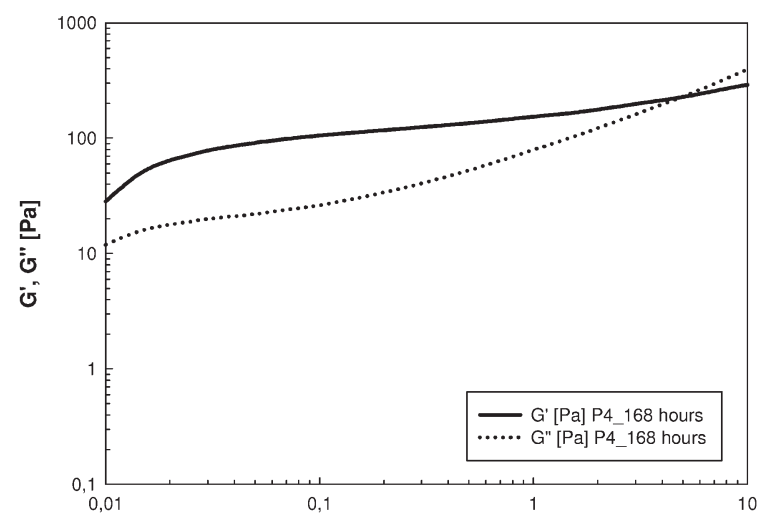

b) P4 at $168 \mathrm{~h}$

f, $[\mathrm{Hz}]$
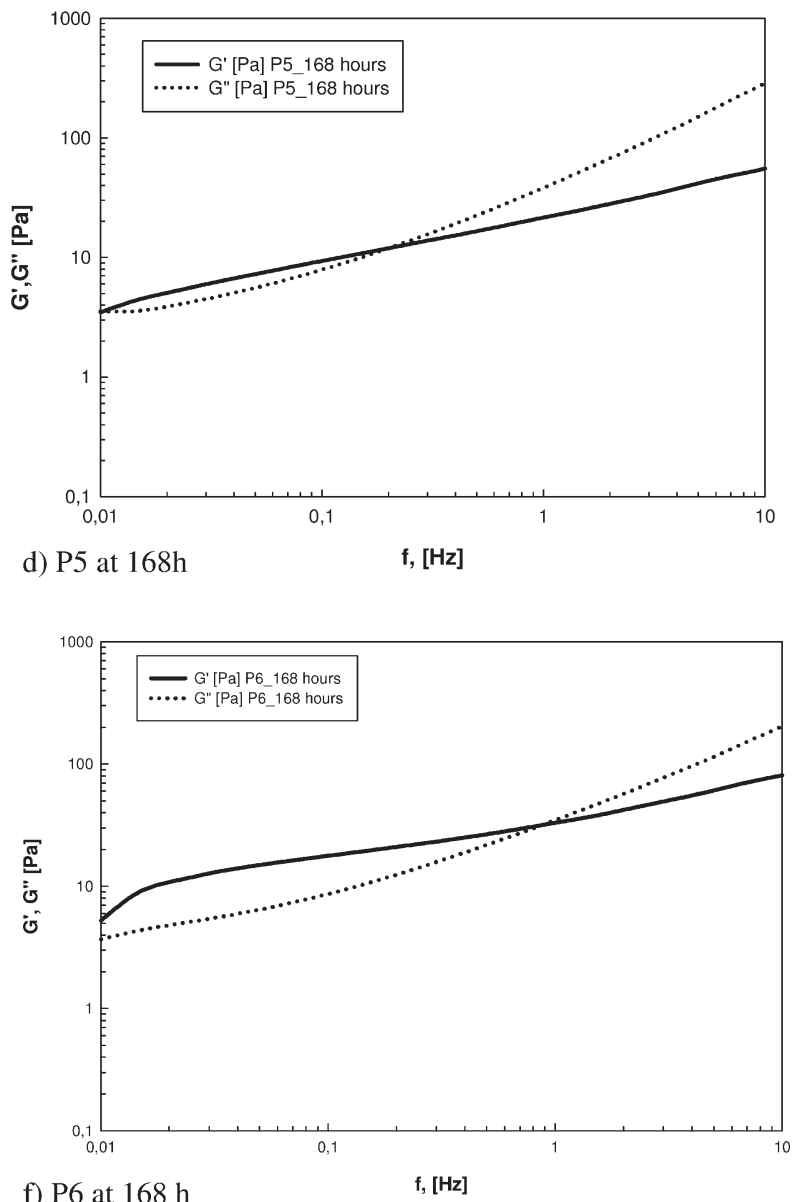

Figure 9 Dynamic tests of P4, P5, and P6 at 1 and 168 h: frequency sweeps. (a) P4 at 1h, (b) P4 at 168 h, (c) P5 at 1 h (d) $\mathrm{P} 5$ at $168 \mathrm{~h},(\mathrm{e}) \mathrm{P} 6$ at $1 \mathrm{~h},(\mathrm{f}) \mathrm{P} 6$ at $168 \mathrm{~h}$.

Moreover, the evolution of the rheological behavior, from pseudoplastic $(1 \mathrm{~h})$ to almost Newtonian (168 h), of plastisols P5 and, most clearly, on P6, because of the large number of compact aggregates, as explained previously, can be observed.

Comparing plastisols P2 and P4 in Table V (same E-PVC 1 and different dosages of plasticizer), the lower the dosage of DIDP the higher the viscosity and the more pronounced the aging process, as expected.

\section{Plastisol's viscoelastic properties during aging}

The application of oscillatory rheometry, through a frequency sweep test for a fixed stress, in the linear viscoelastic regime, allows a further evaluation of the material structure by the evolution of the two moduli $\left(G^{\prime}\right.$ and $\left.G^{\prime \prime}\right)$ during the aging period of the plastisol.

Analyzing the dynamic results in Figure 9, in plastisols P4 and P6 there is a predominant elastic $\left(\mathrm{G}^{\prime}>\mathrm{G}^{\prime \prime}\right)$ 
behavior during the frequency sweep tests at $1 \mathrm{~h}$. On the opposite side, on such an earlier aging step of $\mathrm{P} 5$, the viscous forces seem to override the elastic ones. Nevertheless, at $168 \mathrm{~h}$, for low frequencies, P5 has a similar dynamic behavior to P4 and P6 though the elastic module does not show a predominance as high as in the case of the two last plastisols. Correlating with the data from Tables III and V, P5 shows the highest hysteresis area and a very large decrease of $d_{50}$ just after the paste preparation. Moreover, the resin in P5 (E-PVC 3) is composed of many large structured aggregates moderately compact. Thus, just $1 \mathrm{~h}$ after the plastisol's preparation, the viscous forces still predominate $\left(G^{\prime \prime}>G^{\prime}\right)$ because of the high number of large aggregates that result in a high plasticizer availability in the mixture. This tendency starts to change as time elapses because of the impregnation of the aggregates by the DIDP. E-PVC5 is the sample with lowest $d_{F}$, thus impregnation of the aggregates is easier which leads to alterations in the rheological behavior, with a slight predominance of the elastic module. This is not the case for P6, with a stable behavior in $d_{50}$ and hysteresis. In this case the number of structured aggregates is not as large as in P5, thus, initially, a predominance of the elastic modulus is observed. As time passes, and because these aggregates are very compact [resulting from a latex with a wide size distribution as can be observed by SEM, Fig. 4(c)], solvation is more difficult and the decrease on the availability of DIDP is not so pronounced. This explains the high stability of this plastisol. The wide PSD of P6 and its evolution during aging, correlates directly with the observed on the tests on Figure 9(e,f). In the case of $\mathrm{P} 4$, produced with E-PVC1, the resin has got the lowest number of structured and compact aggregates [Fig. 2(a)]. In this case aggregates are altogether more friable. Therefore, this is the plastisol with the strongest elastic behavior and a more pronounced aging. The same happens for P1 produced with the same resin.

Analyzing the modules to higher frequencies, the observed inversion to viscous $\left(G^{\prime \prime}>G^{\prime}\right)$ indicates the viscous emerging behavior of all plastisols. The inversion point of P5 and P6 is lower than in P4, indicating the presence of strong elastic forces in the latter one.

Table VI summarizes the limit viscosity at 24 and $168 \mathrm{~h}$, some features of the dynamic tests at $0.1 \mathrm{~Hz}$ and the frequency for which the moduli reach the same value $\left(G^{\prime}=G^{\prime \prime}\right)$, that is, with the same contribution of the viscous and elastic components.

Again, the markedly stability of P6 during aging, followed by a predominant elastic behaviour $\left(\mathrm{G}^{\prime}\right.$ $\left.>\mathrm{G}^{\prime \prime}\right)$ in almost all plastisols until and after $24 \mathrm{~h}$ is observed. The exception corresponds to P5, where the viscous forces are predominant until $24 \mathrm{~h}$, mainly because of the higher hysteresis area during all the aging period.

Referring to plastisols P1 and P2 (effect of thermal stabilizer on paste rheology), the variation in the viscoelastic behavior is more pronounced in the absence of stabilizer (Table VI). Moreover, the two modules are generally larger without stabilizer. As for the influence of the plasticizer dosage (compare plastisols P2 and P4), the limit viscosity is higher when the plasticizer concentration decreases, and aging is more pronounced in this case, the absolute value of the modules increasing and the elastic behavior becoming more pronounced.

Comparing, for the different plastisols, the frequency for which both modules are equal, there is a general decrease in that frequency from $1 \mathrm{~h}$ to $168 \mathrm{~h}$, translating the increase in the viscous component $\left(G^{\prime \prime}\right)$ through the aging period. The only exception corresponds to P1, where a high increase in that frequency is observed, thus the elastic component keeps a very high predominant behavior during all the aging period, the viscoelastic behavior becoming even more pronounced with time, as a result of the absence of the stabilizer.

Relating the viscoelastic behavior with the type of aggregates in the paste, the more open aggregates with a higher propensity for solvation, lead to plastisols with a more pronounced elastic behaviour (plastisol P4). Plastisols P6 and P5, with a very high number of compact and large aggregates, thus less elastic, do not exhibit a pronounced elastic behavior. In fact, in the case of $\mathrm{P} 5$, the plastisol with the highest number of large and structured aggregates, with very low elasticity, the behaviour is almost viscous during all the aging period.

\section{CONCLUSIONS}

The study of the relationship between the rheological behavior of the plastisols and the properties of the original dispersion polymer's powder are still playing great interest because of their worldwide commercial appliances. The LDS technique, applied directly to the particles suspended in the paste, gives relevant information about the evolution of the PSD with time and, thus, about the interaction degree with the plasticizer and the strength of agglomerates. Namely, the effect of a common thermal stabilizer used in the formulation (P1 and P2) or, the powder original properties, as a result of a different production process (P2 and P3) can be evaluated. Also, keeping the paste formulation, a different surfactant used in the polymerization process can provide a new rheological behavior (P4 and P5) as a result of the different characteristics of the 
aggregates produced. Moreover, for the same plasticizer on paste formulation, the limit viscosity and hysteresis area (P4, P5, and P6) is closely related with the PSD evolution during aging.

Summarizing, the rheology of the so called plastisols is a complex subject where many variables associated with the industrial formulations, such as: polymerization ingredients, thermal stabilizers, PSD of powders, and the presence of (non)friable agglomerates, all of them have a certain degree of interaction. Thus, depending on the application and therefore on the processing conditions of the plastisol to the final product, a careful selection of the polymer type and paste formulation should be performed. Knowing how the aforementioned parameters interact and influence the paste rheology can lead to an optimized strategy to improve, for instance, process conditions to minimize cost and/or maximize the productivity of a given PVC final product.

\section{NOMENCLATURE}

PSD particle size distribution

DOP Di-octyl Phtalate

DIDP Di-isodecyl Phtalate

E-PVC Poly(vinyl chloride) from the emulsion production process

SEM Scanning electron microscopy

SLS Sodium Lauryl Sulphate

SABS Sodium n-alkyl $\left(\mathrm{C}_{10}-\mathrm{C}_{13}\right)$ benzene sulphonate

LDS Laser diffraction Technique

P1 6 Plastisol's samples

$d_{50} \quad$ Median of the particle size distribution, $\mu \mathrm{m}$

$d_{10} \quad$ Particle diameter corresponding to the $10 \%$ cumulative percentage, $\mu \mathrm{m}$ $d_{90} \quad$ Particle diameter corresponding to the $90 \%$ cumulative percentage, $\mu \mathrm{m}$

$d_{F} \quad$ Mass fractal dimension

$\mathrm{G}^{\prime} \quad$ Storage modulus, $\mathrm{Pa}$

$\mathrm{G}^{\prime \prime} \quad$ Loss modulus, $\mathrm{Pa}$

$K \quad$ Fikentscher $K$ value (applied for commercial polymers)

$f \quad$ Frequency, $\mathrm{Hz}$

\section{Greek letters}

$\mu \quad$ Viscosity, Pa s

$\gamma \quad$ Shear rate, $1 / \mathrm{s}$

$\tau \quad$ Shear stress, $\mathrm{Pa}$

\section{References}

1. Saeki, Y.; Emura, T. Prog Polym Sci 2002, 27, 2055.

2. Sarvetnick, H. A. Plastisols and Organosols; Van Nostrand Reinhold: New York, 1972.

3. Collins, E. A.; Hoffman, D. J. J Colloid Interface Sci 1979, 71, 21.

4. Rasteiro, M. G.; Antunes, E. Particulate Sci Technol 2005, 23, 361.

5. Nakajima, N.; Harrel, E. R. J Appl Polym Sci 2005, 95, 448.

6. Nakajima, N.; Harrel, E. R. J Colloid Interface Sci 2001, 238, 116.

7. Nakajima, N.; Harrel, E. R. J Colloid Interface Sci 2001, 238, 105.

8. Espiard, Ph.; Peres, R.; Soares, C.; Ernst, B. Rheology of PVC Plastisols, PVC 96-New perspectives; The Institute of Materials: Brighton, 1996.

9. Biggs, S.; Habgood, M. Chem Eng J 2000, 80, 13.

10. Schmidt, P. W. In The Fractal Approach to Heterogeneous Chemistry: Surfaces, Colloids, Polymers, Use of Scattering to Determine the Fractal Dimension; Avnir., D., Ed.; Wiley: New York, 1989; p 67.

11. Tanner, R. I. Engineering Rheology; 2nd ed.; Oxford Engineering Science Series, 2000. 